\title{
Factors Contributing to Lower than Expected Recovery Rates of HIV Negative Children on the Therapeutic Feeding Program
}

\author{
Ephias Gudyanga ${ }^{1}$, Nyashadzashe Sharon Gudyanga ${ }^{2}$, Anna Gudyanga ${ }^{1}$, \\ Ropafadzo Shumirai Tshalibe ${ }^{2}$ \\ ${ }^{1}$ Midlands State University, Faculty of Education, Department of Educational Foundations, Management and Curriculum Studies, Gweru, \\ Zimbabwe \\ ${ }^{2}$ Midlands State University, Faculty of Science and Technology, Department of Food Science and Nutrition, Gweru, Zimbabwe
}

\section{Email address:}

gudyangae@msu.ac.zw (E. Gudyanga), gudyangaa@msu.ac.zw (A. Gudyanga), nyashasharon@gmail.com (N. S. Gudyanga), tshalibers@msu.ac.zw (R. S. Tshalibe)

\section{To cite this article:}

Ephias Gudyanga, Nyashadzashe Sharon Gudyanga, Anna Gudyanga, Ropafadzo Shumirai Tshalibe. Factors Contributing to Lower than Expected Recovery Rates of HIV Negative Children on the Therapeutic Feeding Program. American Journal of Health Research. Vol. 3, No. 1, 2015, pp. 24-36. doi: 10.11648/j.ajhr.20150301.15

\begin{abstract}
The study sought to find out factors contributing to lower than expected recovery rates of HIV negative children on the therapeutic feeding program. Qualitative design was employed. Twenty (20) caregivers were interviewed at Gweru District Health Offices in Zimbabwe. Findings indicated that socio-economic factors, level of education and caring practices of the caregiver and the cultural practices to a larger extent contributed to the lower than expected recovery rates of HIV negative children on the therapeutic feeding program. Epi Info, used as database software showed that the exposure variables had an association with the outcome (recovery). Stunted children had 89\% less chances of recovering, breast feeding children had $83 \%$ more chances of recovering unlike those not breast fed. Socio demographic factors had more impact on the recovery of the child. The Zimbabwean government should spend more money on quality nutritional programs to improve the state of malnutrition. More nutrition campaign is inevitable in an effort to promote health.
\end{abstract}

Keywords: Therapeutic, HIV, Recovery Rate, Anthropometric, Malnutrition, Mortality, Morbidity

\section{Introduction}

The study sought to find out factors contributing to lower than expected recovery rates of HIV negative children on the therapeutic feeding program. The nutrition department of the Gweru District Health Offices (GDHO) in Zimbabwe among others implements Integrated Management of Malnutrition and worked hand in hand with Adventist Development and Relief Agency (ADRA)-Zimbabwe which implements the supplementary feeding program (SFP). The nutrition department selects areas and households to receive food aids by targeting people at risk.

\section{Background and Context}

It has been noted that one in every three preschool children in the developing world is malnourished [1]. They are therefore more likely to have impaired immune systems and cognitive development and greater susceptibility to diet related chronic diseases [2]. Developing countries such as Zimbabwe have made strides in reducing child malnutrition over the past few decades [1]. According to [1], the prevalence of underweight children under 5 years of age in the developing countries was $46.5 \%$ in 1970 . By 1995 it had dropped to $31 \%$, indicating that while past progress has been substantial, it still has a long way to go [1].

According to [3], malnutrition remains one of the most causes of morbidity and mortality among children throughout the world. According to global estimates, $35 \%$ of all child mortality is attributable to maternal and child under nutritionapplying these estimates to Zimbabwe, malnutrition may contribute to nearly 12000 deaths per year [3]. The effects of malnutrition come in two forms which are acute malnutrition and chronic malnutrition. The Government of Zimbabwe through the National Nutrition Unit introduced the program 
Community Management of Acute Malnutrition (CMAM) made of the stabilisation care and the outpatient therapeutic care.

Stabilisation care is meant to provide in-patient treatment to children with severe acute malnutrition to which treatment leads the child to graduate for outpatient therapeutic treatment (OTT). Patients with severe acute malnutrition without complications are enrolled in the OTT. Patients on outpatient therapeutic care are given the main therapeutic food called plumpy-nut or ready to use therapeutic food (RUTF) up until the condition would have improved which normally takes about 8 weeks for a child who is admitted in the program. They are provided with RUTF in accordance with recommendations for their age and weight.

ADRA Zimbabwe continues to implement two projects that are both funded by World Food Programme (WFP). The first project is the Nutrition Support for malnourished individuals in the following categories: (a) people on antiretroviral therapy (ART) and tuberculosis (TB), (b) children 6-59 months and (c) pregnant and lactating mothers. The goal of the project is to enhance the quality of life of people living with HIV/AIDS and those on TB treatment and other vulnerable groups with a purpose to improve food, nutrition and livelihoods security. The project is curative and combines food aid and promotes adherence to treatment. This project is currently in the entire district, that is, Gweru urban and rural in Zimbabwe.

According to the report compiled in December 2013, household food insecurity assessments were done for the admitted patients. In the Gweru urban, food insecure households received household rations of maize meal ( $5 \mathrm{~kg} /$ person), vegetable oil $(750 \mathrm{ml} /$ person) and beans up to a maximum of 5 members per household. A total of 379 households were assisted with food in the month of June 2014. In the rural areas food insecure households received rations of maize $(10 \mathrm{~kg} /$ person), peas or beans and vegetable oil $(0.6 \mathrm{~kg} /$ person and corn-soya-blend porridge $(10 \mathrm{~kg}$ per person).

Malnutrition literally means bad nutrition and technically includes both over and under nutrition. WFP defines malnutrition as a state in which the physical function of an individual is impaired to the point where he or she can no longer maintain adequate bodily performance processes such as growth, pregnancy, lactation, physical work, resisting and recovering from disease [4].

Findings confirm that more than a third of the world's children are affected by malnutrition. Approximately $43 \%$ of children (230million) in developing countries are stunted [5]. Research estimated that approximately $52 \%$ of approximated deaths among children below 5 years occur after the first 6 months of life in developing countries [6]. These estimations were generated using population values, historical data from 36 countries, current infant mortality rates and mortality rates of under-fives [7].

Nutrition is basically a human need that remains unmet for many children and therefore is unable to achieve their full genetic developmental potential [8]. Health and nutrition problems during childhood are a result of mostly underprivileged populations related to unsatisfactory food intake or even repeated and severe infections. Findings confirmed that the high magnitude of under nutrition continues to hamper mental development and physical growth of more than one third of the world's children [9]. Developing countries have high prevalence of parasitic and bacterial diseases thereby contributing to malnutrition. Similarly, malnutrition increases one's susceptibility and severity of infection which is a major characteristic of illness and death from disease [10].

Maternal and child under nutrition remains highly pervasive and prevalent in middle and low income countries [1]. Under nutrition, an important determinant of maternal and child under nutrition encompasses wasting, stunting and micronutrient (vitamins and minerals) deficiencies as one form of malnutrition [11].

There are various anthropometric indices that can be useful in assessment of child growth status. Among them height-forage (stunting), weight-for-height (wasting) and weight-forage (underweight) provide a comprehensive description. Height-for-age shows performance in terms of linear growth and measures long term growth faltering. In other words it reflects chronic restriction of child's potential growth [9]. Low height-for-age reflects the cumulative effects of many insults experienced during infancy and early childhood. It begins at birth and continues through the initial 42 months of life after which time it is reversible [12].

Weight-for-height reflects body proportion particularly sensitive to disturbances that have to do with growth. Weight-for-age represents a convenient synthesis of both linear and body proportion [9]. It is widely recognised that the first several years of life represents a window of opportunity to prevent irreversible growth faltering. Faltering in length is more pronounced during the first 18 months and extends even to 40 months. Faltering in weight after 12 months causes the child to be stunted and of low-weight-age although weight for height ratio improves rapidly. This suggests that after 12 months, the process of stunting can continue for another 2 years despite adequacy of weight gain. Failure to gain weight is a good signal of inadequate nutrition and or illness but does not necessarily mean that the child is growing taller appropriately if there is adequate weight gain [12].

Weight for age is a strong predictor of long term mortality. In contrast, weight for height closely shows the current nutritional status which in turn may be greatly affected by seasonal deviations in availability of food as well as recent infectious diseases. Weight for age is less subject to interpretational problems caused by reverse causality as it is more resistant to short-lived conditions [7]. Low weight-forage is reversible and is concentrated during the first 12 months of life [12]. It is thus more useful to consider wasting and stunting than considering underweight [11].

Babies born at full term but of low birth weight are likely to have had intrauterine growth restriction. Children may become stunted if with optimum breast milk but not 
receiving adequate quality and quantity of complementary foods after 6 months of age [11]. Increasing feeding frequencies can reduce breast feeding and the benefits derived from breast milk. Further the other traditional recommendation of adding oil to foods can further aggravate poor nutrition as it further dilutes the density of micronutrients in the diet, which are almost certain to be inadequate. Characteristics of the diet, child appetite, and caregiver behaviours likely interact to influence intake from complementary foods. Caregiver behaviour includes the level of encouragement provided to the child when feeding, feeding frequencies, quality of caregiver-child interactions as well as the environment where feeding takes place [12].

Health and poverty are intertwined inextricably. Being able to earn a living, feed a family, breast feed, attend school or work to grow food, depend on the basis of good health. Extreme poverty undermines a great range of human capabilities, possibilities and opportunities. People enduring poverty are usually less educated as they often have less knowledge about the activities that promote health and do not even know when to access the health centre. A typical example is that, women with financial resources access antenatal services more frequently and do not suffer birthing outcomes than poor women. These effects extend beyond birth as children born to women with 5 years or more of primary school education, has a $40 \%$ higher survival rate than those born to women with no education [13]. A person is considered to be in complete poverty when one fails to sufficiently satisfy his or her basic needs which include, primary education, water, health, and food as well as community participation [14].

It should be known that, it is necessary to have enough food available per person nationally but not sufficient condition for that country to achieve food security; households must also be able to access food available in order to achieve adequate nutrient intakes for their children on a sustainable basis [1]. Similarly, increases in the amount of income available per person are necessary but not sufficient condition for eradicating poverty.

If national incomes and democracy are not improved, this will affect investment in health environments, women's education, women's relative status and food availability. Of the explanatory that represent the underlying determinants, women's education is found to have the strongest impact on child malnutrition [13].

Low status restricts women's opportunities, diminishes interaction with others, harbour transmission of new technology and also damages self-esteem [15]. Status is important for autonomy and control over resources as well as the mother's physical and mental health. Their physical condition is closely associated with care quality they give even prior to giving birth [16]. When a woman is in poor physical and mental health, she therefore provides very low health care quality to her children after birth even the quality of breast feeding. Generally, when the care of the child's mother suffers, the child's care suffers as well thereby compromising the child's health $[15,2]$.
Only children who suffer from complications require hospital admission and not necessarily all children with severe acute malnutrition (SAM). Home based management with Ready-to-Use Therapeutic Food (RUTF) has been found to be associated with better outcome than standard therapy in the hospital. Advantages of home based management include, more time available to mothers to spend with family and mothers are able to look after family responsibilities simultaneously. Furthermore, children have reduced exposure to infections in the hospital and continue to receive care after being discharged [17].

The prevention and treatment of acute malnutrition through emergency food aid programs, such as therapeutic feeding programs, can reduce the progression towards SAM. Generally, the programs operate with admission and discharge criteria based on the anthropometric measurements of the child. Currently, a number of international agencies are implementing these programs worldwide, despite lack of validated evidence showing their overall effectiveness of the treatment foods [18]. The use of RUTF has become increasingly popular for the treatment and prevention of malnutrition.

RUTF are high energy foods which are fortified with vitamins and minerals, each packet providing 500Kcal of energy. Packaging allows easy handling and prevents contamination of the product between feedings. Peanut-based RUTF consists of milk powder (30\%), sugar $(28 \%)$, peanut butter $(25 \%)$, vegetable oil $(15 \%)$ and vitamin and mineral premix (1.6\%) [19]. It also contains electrolytes and micronutrients [19]. The success of RUTF has been attributed to its specialised formula that meets the nutritional needs of children, not susceptible to bacterial growth as it is oil based and is eaten uncooked and therefore ideal for delivering many micronutrients that might otherwise be destroyed by heat [19]. No data has been collected on nonresponsive rates of children on the program as well as data on the intra-household food sharing practices with RUTF provided. A study conducted in Malawi comparing treatment outcomes of RUTF and corn soya blend feeding interventions concluded that intra-household food sharing was a likely reason for the children reporting a lower than expected consumption of the treatment food [10].

High default rates in emergency therapeutic feeding programs are often a cause of low recovery rates [19]. The problem of default is an important one that reduces recovery and may be unknown to programme managers, be increasing mortality. Ashworth managed to make reviews of published programmes that implemented community-based rehabilitation of severely malnourished children. Results showed common shortcoming of inadequate appreciation of the need to provide regular, energy and nutrient dense food during the program to allow for recovery. Some studies also achieved low weight gain and low recovery rates despite providing high energy supplements [19].

In a clinical trial in severely malnourished children undertaken in a therapeutic feeding centre in Senegal, energy intakes, rates of weight gain and time to recovery were all 
significantly better in those receiving RUTF from phase 2 than those in inpatient care receiving F100. There were successful home-based trials undertaken in Malawi to evaluate the efficacy of RUTF. Rates of weight gain and the proportion of children recovering to $100 \%$ weight-for height were significantly better in RUTF groups [19].

It is against this background that the we found it imperative to study the factors contributing to the lower than expected recovery rates of HIV negative children (659months) who are on therapeutic feeding program.

The research question which guided this study was: What are the factors contributing to lower than expected recovery rates of HIV negative children on the therapeutic feeding program?

\section{Methodology}

A qualitative design was conducted to allow researchers to obtain information on the association between exposure and outcome. The study targeted 32 malnourished children who tested HIV negative on admission into the therapeutic feeding program conducted at Gweru Health District Health Offices (GHDHO).

To make sure that there was a fair representation of the malnourished children, a total of 20 caregivers, participated in the study. This was done to ensure viable results from which we made conclusions. 10 caregivers were selected as the 'control' and the other 10 being the cases. The 'control' defined as the group of children who achieved $80 \%$ recovery rate in a period of 6 - weeks and the 'cases' being those who failed to recover in the same period.

Convenient sampling was carried out and caregivers for the 'cases' and 'controls' who fitted in the inclusion and exclusion criteria were selected on Fridays when they came with malnourished children for their review and supply of RUTF.

Structured interview questions on questionnaire format were used on 20 caregivers. Researchers administered interviews as well as filling in the questionnaire forms on behalf of participants. Such procedure made it easy for data analysis however bias was minimised to ensure trustworthiness of data generated. On Fridays we carried out interviews at Gweru District Health Offices. The first 20 caregivers who came with children for their review and supply for RUTF were selected for the interviews. We were introduced by the Nutrition assistant who was managing the malnourished children. We got the child details from the admission and discharge registers. As part of the research ethics, we got ethical clearance from the University and took it to Nutritionist at Gweru District Health Offices (GDHO). Permission was granted by the District Medical Officer at GDHO to carry out interviews at GDHO. Participants were interviewed after they had been informed about the objectives of the study. They freely and willingly consented in writing to participate in the study. They were informed to withdraw at any moment if they so wished. Interviews were used because of their capabilities of probing and producing larger amounts of data in a short time.

Epi Info version 3.5.1 was used as database software to capture data in electronic format. It was further used to generate frequencies of the demographic characteristics of respondents, calculate mean and standard deviations of the continuous variables, also to come up with descriptive statistics in relation to child recovery and to calculate the odds ratios, confidence intervals (C.I.) and $\mathrm{P}$ values of the variables in relation to child recovery. SPSS 16.0 (Statistical Package for the Social Sciences) was also used to calculate the reduced coping strategy index (reduced CSI) which compares food security across different contexts using Non parametric tests particularly the Chi square test. This was done to come up with the variables that had an association with recovery, which were statistically significant. Microsoft Excel was used to create the reduced Coping Strategy Index graph.

\section{Results}

The study sought to investigate factors contributing to lower than expected recovery rates of HIV negative children on the therapeutic feeding program. The findings were as follows:

\subsection{Demographic Characteristics of Respondents}

Table 1. Demographic characteristics of participants.

\begin{tabular}{|c|c|c|c|}
\hline Variable & Category & Frequency & Proportion $\% \mathrm{~N}=20$ \\
\hline \multirow{2}{*}{ Household Head } & Male & 18 & 90 \\
\hline & Female & 2 & 10 \\
\hline \multirow{5}{*}{ Marital status of household head } & Married living together & 16 & 80 \\
\hline & Married living apart & --- & ---- \\
\hline & Divorced/Separated & 2 & 10 \\
\hline & Widow/Widower & 1 & 5 \\
\hline & & 1 & 5 \\
\hline \multirow[t]{2}{*}{ Household head source of income } & Formal & 2 & 10 \\
\hline & Unemployed & 13 & 65 \\
\hline VARIABLE & CATEGORY & FREQUENCY & $\begin{array}{l}\text { PROPORTION\% } \\
\mathrm{N}=20\end{array}$ \\
\hline & $<150$ & 11 & 55 \\
\hline Income level & $>150$ & 9 & 100 \\
\hline
\end{tabular}




\begin{tabular}{|c|c|c|c|}
\hline Variable & Category & Frequency & Proportion $\% \mathrm{~N}=\mathbf{2 0}$ \\
\hline \multirow{3}{*}{ Relationship of Caregiver to child } & Aunt & 1 & 5 \\
\hline & Grandmother & 1 & 5 \\
\hline & Mother & 18 & 90 \\
\hline \multirow{4}{*}{ Age of caregiver } & $19-25$ & 7 & 35 \\
\hline & $26-35$ & 9 & 45 \\
\hline & $36-45$ & 3 & 15 \\
\hline & $>46$ & 1 & 5 \\
\hline \multirow{3}{*}{ Level of education of caregiver } & Primary & 12 & 60 \\
\hline & Secondary & 8 & 40 \\
\hline & Married living together & 15 & 75 \\
\hline \multirow{3}{*}{ Marital status of caregiver } & Married living apart & 2 & 10 \\
\hline & Divorced/Separated & 2 & 10 \\
\hline & Widow/Widower & 1 & 5 \\
\hline \multirow{3}{*}{ Caregiver source of living } & Informal & 5 & 25 \\
\hline & Formal & 2 & 10 \\
\hline & Not employed & 13 & 65 \\
\hline \multirow{2}{*}{ Sex of child } & Male & 5 & 25 \\
\hline & Female & 15 & 75 \\
\hline Variable & Category & Frequency & $\begin{array}{l}\text { Proportion \% } \\
\mathrm{N}=20\end{array}$ \\
\hline \multirow{2}{*}{ Father alive } & Yes & 19 & 95 \\
\hline & No & 1 & 5 \\
\hline \multirow{2}{*}{ Mother alive } & Yes & 19 & 95 \\
\hline & No & 1 & 5 \\
\hline \multirow{3}{*}{ Reason of admission } & Kwashiorkor & 7 & 35 \\
\hline & Marasmic-kwashiorkor & 1 & 5 \\
\hline & Marasmus & 12 & 60 \\
\hline
\end{tabular}

Respondents in Table 1 showed that a greatest percentage of the households were male headed $(90 \%)$ and living with their partners. A greater number of them were unemployed (65\%). Those employed showed a greater percentage of 55\% with income level less than 150 USD. $90 \%$ of the children were taken care of by their biological mothers with the remaining percentage taken care of by the aunt and grandmother. A greater percentage showed that the highest level of education of the caregivers was primary and $40 \%$ having reached secondary level and a greater percentage of them being unemployed (65\%).

\subsection{Other Demographic Characteristics}

Table 2. Further demographic characteristics

\begin{tabular}{lll}
\hline Variable & Mean & Std Deviation \\
\hline Age(household head) & 35.40 & 8.22 \\
Age of child(months) & 18.00 & 9.09 \\
Variable & Mean & Std Deviation \\
Weight & 7.34 & 1.40 \\
MUAC & 11.33 & 0.71 \\
Height & 73.28 & 8.51 \\
Length of stay & 5.40 & 1.50 \\
Wean age & 11.17 & 6.18 \\
\hline
\end{tabular}

Table 2 household heads had a mean age of 35 years. Children who were admitted on the therapeutic program had a mean age of $18 \pm 9.1$ SD months, mean weight of $7.4 \mathrm{kgs}$, mean mid-upper-arm circumference (MUAC) of 11.33, and mean height of 73.28 and their length of stay in the program averagely for 5.4 weeks. Children who were no longer breast feeding were weaned at an average age of 11 months.

\subsubsection{Social Factors}

Table 3. Social factors.

\begin{tabular}{llll}
\hline Characteristics & Category & $\begin{array}{l}\text { Child recovery } \\
\text { Recovered }\end{array}$ & $\begin{array}{l}\text { Child recovery } \\
\text { Not recovered }\end{array}$ \\
\hline \multirow{2}{*}{ Age of household head(years) } & -35 & $3(37.5 \%)$ & $5(62.5 \%)$ \\
& +35 & $7(58.3 \%)$ & $5(41.7 \%)$ \\
Caregiver level of education & Primary & $4(33.3 \%)$ & $8(66.7 \%)$ \\
& Secondary & $6(75.0 \%)$ & $2(25.0 \%)$ \\
& $19-25$ & $2(40.0 \%)$ & $3(60.0 \%)$ \\
Caregiver age(years) & $26-35$ & $6(66.7 \%)$ & $3(33.3 \%)$ \\
& $36-45$ & $1(33.3 \%)$ & $2(66.7 \%)$ \\
& $>46$ & $1(33.3 \%)$ & $2(66.7 \%)$ \\
\hline
\end{tabular}


Table 3 shows that more children (58.3\%) recovered with household heads aged 35 years and above and only $37.5 \%$ recovered having household heads with less than 35 years of age. Only $25 \%$ of children failed to recover having caregivers with secondary level of education and $66.7 \%$ failed to recover with primary level of education. A greater percentage of child recovery $(63.6 \%)$ was shown in children who are taken care of by caregivers above 25 years of age and only $33.3 \%$ recovered with caregivers below 25 years of age.

\subsubsection{Health Factors}

Table 4. Health factors.

\begin{tabular}{llll}
\hline Characteristics & Category & Child recovery Recovered & Child recovery Not recovered \\
\hline \multirow{2}{*}{ Nutritional status } & Stunted & $3(27.3 \%)$ & $8(72.7 \%)$ \\
& Not stunted & $7(77.8 \%)$ & $2(22.2 \%)$ \\
Age of child(months) & -18 & $7(58.3 \%)$ & $5(41.7 \%)$ \\
& +18 & $3(37.5 \%)$ & $5(62.5 \%)$ \\
Sex of child & Male & $3(60.0 \%)$ & $2(40.0 \%)$ \\
& Female & $7(46.7 \%)$ & $8(53.3 \%)$ \\
\hline
\end{tabular}

Table 4 shows that higher child recovery of $77.8 \%$ was achieved by children who were not stunted and $72.7 \%$ of stunted children failed to recover. $60 \%$ of males recovered and only $46.7 \%$ of females recovered. Of the children below

18 months of age, $58.3 \%$ managed to recover and having $62.5 \%$ of children above 18 months of age failing to recover.

\subsubsection{Caring Practices}

Table 5. Caring practices.

\begin{tabular}{llll}
\hline Characteristics & Category & Child recovery Recovered & Child recovery Not recovered \\
\hline \multirow{2}{*}{ Religious practices agreeing with treatment } & Yes & $6(54.5 \%)$ & $5(45.5 \%)$ \\
& No & $4(44.4 \%)$ & $5(55.6 \%)$ \\
Mother ill and received medication & Yes & $2(66.7 \%)$ & $1(33.3 \%)$ \\
& No & $1(25.0 \%)$ & $3(75.0 \%)$ \\
Child still breast feeding & Yes & $6(75.0 \%)$ & $2(25.0 \%)$ \\
& No & $4(33.3 \%)$ & $8(66.7 \%)$ \\
Wean age & -24 & $2(22.2 \%)$ & $7(77.8 \%)$ \\
\hline
\end{tabular}

Table 5 shows that children still breast feeding recovered to a greater extent $(75 \%)$ and $66.7 \%$ of non-breast feeding children failed to recover. $77.8 \%$ of children weaned below 24 months of age failed to recover as compared to $33.3 \%$ of children weaned above 24 months who failed to recover. $55.6 \%$ of children with caregivers who follow religious and cultural practices which do not agree with the treatment of the child, failed to recover and $54.5 \%$ recovered having caregivers who follow religious and cultural practices which agree with the treatment of the child. $75 \%$ of children failed to recover when ill mother did not receive medication and $66.7 \%$ recovered when ill mother received medication.

\subsection{Percentages of Households that Experienced Food Insecurity-Related Conditions in 30days Preceding the Research $(N=12)$}

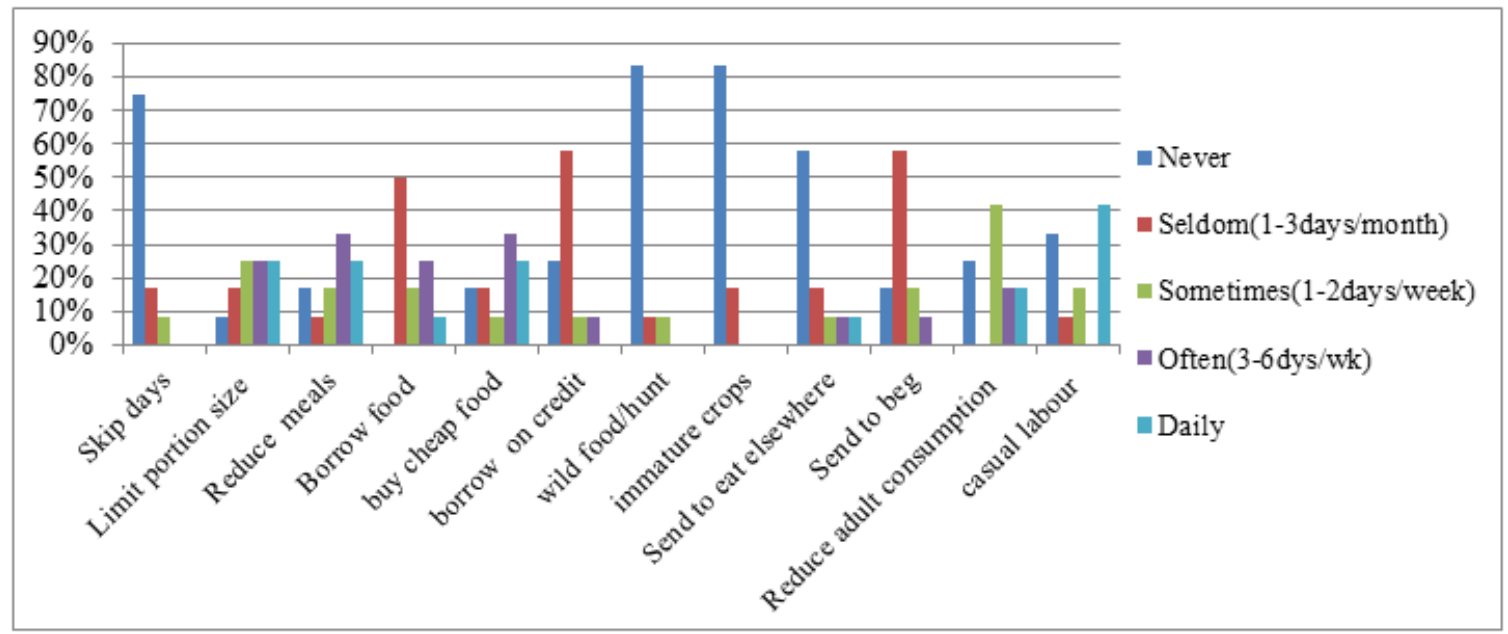

Fig. 1. Households vs Food insecurity-related conditions. 
Fig 1 shows that a larger proportion resorted to using the coping strategies, seldom, sometimes and often reflecting the severity of food insecurity. More than $50 \%$ proportion of households never resorted to using 4 of the coping strategies with a smaller proportion using more of the coping strategies daily.

\subsection{Socio-Demographic Factors Associated with Child Recovery among Malnourished Children Aged 6-59 Months at Gweru District Health Offices, 2014}

Table 6. Socio-demographic factors.

\begin{tabular}{|c|c|c|c|c|c|c|}
\hline Variable & Category & $\begin{array}{l}\text { Recovery } \\
\text { YES }\end{array}$ & $\begin{array}{l}\text { Recovery } \\
\text { NO }\end{array}$ & P.O.R & $\begin{array}{l}95 \% \\
\text { C.I }\end{array}$ & $\begin{array}{l}\mathbf{P} \\
\text { Value }\end{array}$ \\
\hline Age of household head(years) & $\begin{array}{l}+35 \\
-35\end{array}$ & $\begin{array}{l}7(58.3 \%) \\
3(37.5 \%)\end{array}$ & $\begin{array}{l}5(41.7 \%) \\
5(62.5 \%)\end{array}$ & 2.33 & $(0.37 ; 14.6)$ & 0.20 \\
\hline $\begin{array}{l}\text { Source of income(household } \\
\text { head }\end{array}$ & $\begin{array}{l}\text { Unemployed } \\
\text { Employed }\end{array}$ & $\begin{array}{l}7(63.6 \%) \\
6(66.7 \%)\end{array}$ & $\begin{array}{l}4(36.4 \%) \\
3(33.3 \%)\end{array}$ & 0.29 & $(0.04 ; 1.82)$ & 0.11 \\
\hline Earned per month $(\$)$ & $\begin{array}{l}+150 \\
-150\end{array}$ & $\begin{array}{l}6(66.7 \%) \\
4(36.4 \%)\end{array}$ & $\begin{array}{l}3(33.3 \%) \\
7(63.6 \%)\end{array}$ & 3.5 & $(0.55 ; 22.3)$ & 0.11 \\
\hline Caregiver level of education & $\begin{array}{l}\text { Secondary } \\
\text { Primary }\end{array}$ & $\begin{array}{l}6(75.0 \%) \\
4(33.3 \%)\end{array}$ & $\begin{array}{l}2(25.0 \%) \\
8(66.7 \%)\end{array}$ & 6.00 & $(0.81 ; 44.35)$ & 0.05 \\
\hline Caregiver age(years) & $\begin{array}{l}-25 \\
+25\end{array}$ & $\begin{array}{l}3(33.3 \%) \\
7(63.6 \%)\end{array}$ & $\begin{array}{l}6(66.7 \%) \\
4(36.4 \%)\end{array}$ & 0.29 & $(0.04 ; 1.82)$ & 0.11 \\
\hline
\end{tabular}

The chances of child recovering in a household headed by an individual above 35 years is 2.33 times more compared to ones headed by one below 35 years of age. Children headed by an employed member have $71 \%$ more chances of recovering as compared to those having an unemployed household head. The chances of children recovering having household head earning a salary more than 150 USD is 3.5 times more as compared to those earning a salary less than 150 USD. The chances of child recovering with caregivers with secondary level of education are 6 times more as compared to those with primary level. Children with caregivers below 25 years of age have $71 \%$ less chances of recovering as compared to those with caregivers above 25 years of age.

\subsection{Health Care Practices Associated with Child Recovery among Malnourished Children Aged 6-59 Months at Gweru District Health Offices, 2014}

Table 7. Health care practices.

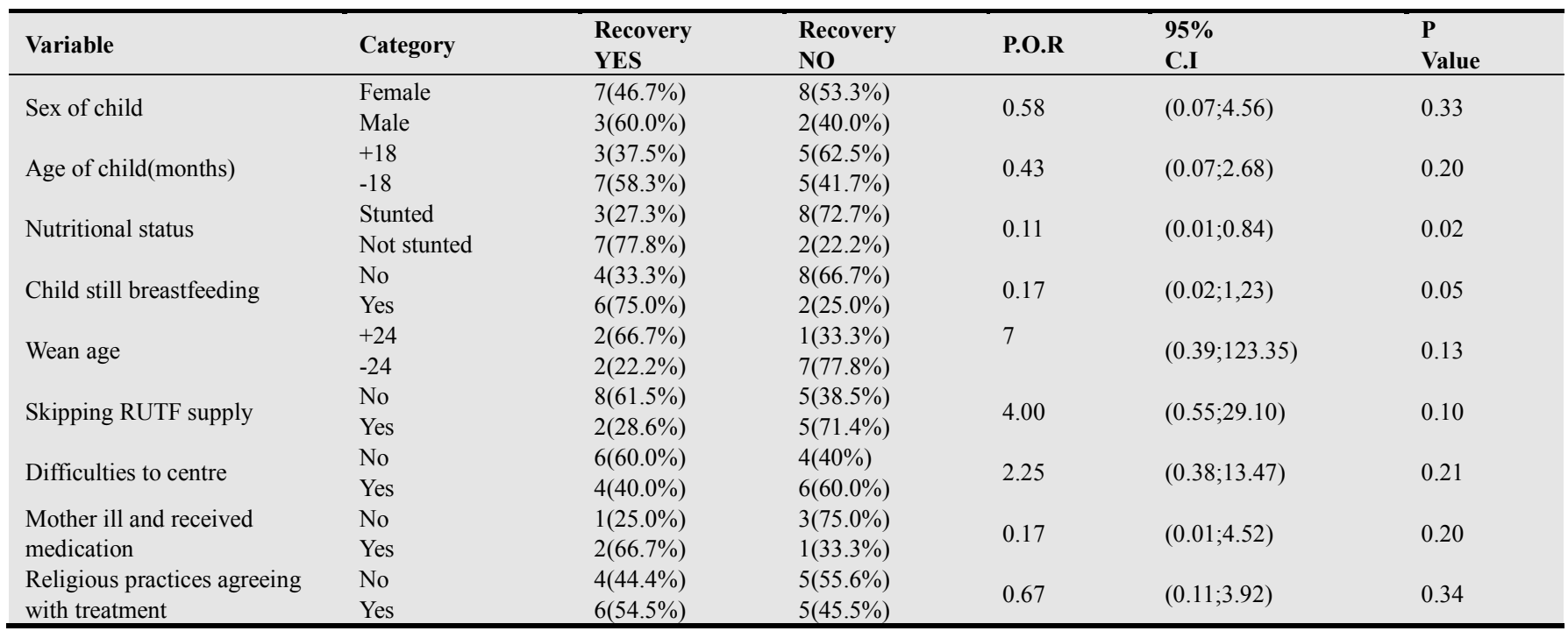

Table 7 shows that female children have $42 \%$ less chances of recovering as compared to males. Children below 18 months of age have $57 \%$ less chances of recovering as compared to those above 18 months of age. Children who are stunted have $89 \%$ less chances of recovering as compared to not stunted children. Breast feeding children have $83 \%$ more chances of recovering as compared to non- breast feeding children. The chances of child recovering when weaned above 24 months of age are 7 times more as compared to children weaned before reaching 24 months. Children who did not skip RUTF supply are 4 times more likely to recover unlike those who skipped RUTF supply. The chances of child recovering not having difficulties to access health centre are to 2.25 times more as compared to those encountering difficulties. Child with ill mother who did not receive medication has $83 \%$ less chances of recovering as compared to those who received medication. Child with mother who follows religious and cultural practices which agree with 
treatment of the child has $33 \%$ chances of recovering as compared to those who follow practices which do not agree with treatment of the child.

\subsection{Reduced Coping Strategy Index}

Table 8. Reduced coping strategy index.

\begin{tabular}{ll}
\hline Variable & P value \\
\hline Skip entire days without eating & $0.007^{*}$ \\
Limit portion size at meal times & 0.116 \\
Reduce number of meals eaten per day & 0.204 \\
Borrow food or rely on help from friends or relatives & 0.119 \\
Rely on less expensive or less preferred foods & 0.116 \\
Purchase or borrow food on credit & $0.011^{*}$ \\
Gather unusual types or amounts of wild food/hunt & $0.001^{*}$ \\
Harvest immature crops & 0.107 \\
Send household members to eat elsewhere & $\mathrm{p}<0.001^{*}$ \\
Send household members to beg & 0.119 \\
Reduce adult consumption so children can eat & 0.074 \\
Rely on casual labour for food & 0.107 \\
\hline
\end{tabular}

Table 8 shows that the following behaviours had the greatest impact on recovery as they showed extent of the severity of food insecurity in a number of households and were statistically significant:

- Skipping entire days without eating $(0.007)$

- Purchasing or borrowing food on credit (0.011)

- Gathering unusual types or amounts of wild food/hunting $(0.001)$

- Sending household members to eat elsewhere $(\mathrm{p}<0.001)$

\section{Discussion}

\subsection{Socio-Demographic Factors}

Eighty $(80 \%)$ of the households were male headed reflecting that males were the dominating figure who made most of the decisions which have great impact on the health status of the entire family. A relatively high number of malnourished children were found in the male headed households. [20], argues that female headed households may be favourable to children as this has to do with making decisions in resource allocation, especially food so that the nutritional status is thus improved. This is in line with findings by [21], that more households were male headed and with a large number of children as compared to female headed households. [20], agrees with the above findings as he stated that chronic malnutrition was significant from households that were headed by males. This means that gender of the household head is essential so as to determine the outcome. Male headed households are associated with stunted children which in this case is consistent with the results [22]. In addition to this, they further postulate that for the small percentage of those who recovered, it could be attributed to the level of education, as with high levels, one is more knowledgeable in issues to do with child care. Furthermore, age of household head is associated with height-for-age and weight-for-age as it also reflects experience [23].

The results that the chances of child recovering in a household headed by an individual above 35 years is 2.33 times more as compared to those below 35 years. We assumed that those above 35 years have better caring practices and have much experience as compared to those below 35 years of age. Informed decisions on food choices can also be made by individuals above 35 years of age.

In the Bangladesh study carried out by [21], the mean age of the malnourished children was 22.6 months in support of the mean age in this study which is 18 months. The reason for such an average is possibly due to the fact that a larger group of them will be suffering consequences due to early weaning and since there are more prone to infectious diseases, they are likey to be malnourished.

When a child increases in age, so is the probability of stunting [24]. This is because chronic malnutrition occurs after weaning as most of the young children will still be breast feeding. It has been noted that surveys carried out in Rwanda and other African countries found out that nutritional vulnerability changed with age due to weaning behaviour as well as disease exposure[25]. According to [25], age of household head is said to have 'life cycle' effects implying that the household in the developmental stage has the effect on the demographic characteristics.

Female children have $42 \%$ less chances of recovering. [21] observed that girls have $44 \%$ higher odds of being severely malnourished than boys. Gender inequalities cause women to be placed at lower status than men such that they tend to eat last and thus the cycle of poverty and malnutrition continues. The Bangladesh study showed that chances for survival for female children were very low as compared to males due to factors such as food sharing practices in the household. This is in line with [22], who found out that the female child had less nutritional status as compared to their male counterparts attributing to the possibility of discriminatory behaviour which favours males [26]. [27] revealed gender as a determinant of underweight as male children were more likely to be underweight as compared to their females.

Children with care givers below 25 years of age have $71 \%$ less chances of recovering. [21] concurred when they noted that the percentage of malnourished children decreased from $37.5 \%$ to $28.1 \%$ with an increase in the age of the caregiver. In other words, child recovery increases with an increase in the caregiver age. We assumed that, young caregivers do not view the importance of time for child-mother interaction and they spend most of their time away from their children. In addition to this, caregivers below 25 years of age are likely to be of school going age such that time for breast feeding as well as food preparation is therefore inadequate such that the child's health is put at risk thereby affecting the recovery rate of the child.

Children with employed household heads had $71 \%$ chances of recovering. Employment boosts the economic status of the household so that the basic needs of the family can be afforded, such as food, shelter, clothing and safe water. [21] stated that socio-economic and health factors have an impact on the nutritional status of an individual and thus the 
recovery rate is also affected. It is therefore recommended that interventions other than health are essential so that values and behaviours of the population are altered [21].

Children with household heads who earned salary above 150USD had 3.5 times of recovering as compared to those earning a salary below 150 USD. [20] is of the idea that household expenditure especially to do with the basics are used to measure the socio-economic status of members. The research assumes that, less income depicts the quality and quantity of resources that are available to each household member. If a balanced diet that contains protein sources that are essential for the child's recovery cannot be afforded, this has an impact on the recovery rate. The income level also depends with the family size.

Family size had no association with the recovery rate of the child, yet it is plausible that the family size affects the resource allocation as large families have limited or no resources available to them due to competition. [20] argues that household size has an impact on the nutritional status. He concluded that, greater numbers have poorer nutritional status than their counterparts as this could reflect unequal access to household resources. Due to this unequal distribution, a large proportion may not have access to adequate food as well as quality health care which to a greater extent affects recovery of the child. [23] are also of the idea that the larger the number of older household members reflects to a larger extent, poorer intra-houseld intake of calories. From another view point, increase in family size means inrease in labour. [23] argue that when there is more labour then more are capable of working for income thus food acquisition becomes esier and there is more time available for child care as well as feeding and hygiene activities which all influence the nutritional status of the household which is closely related to that of the child [1]. It has also been noted that families with more than 4 children have high prevalence of malnutrition and their rate of recovery is affected as there is more pronounced competition for food and health care services.

Some households had members who also needed special attention as the malnourished child. Examples are households with other children below 5 years of age, some being orphans, those with mental and physical challenges and members who have been chronically ill. These results reflect the quality of health care that the malnourished child is likely to get. Time to breast feed is affected, frequencies of meal times as well as preparation of nutritious food is affected due to household members requiring as much attention as that of the malnourished child. Members who are chronically ill have an impact on household health and nutritional outcomes which influence the ability to perform activities that generate money.

\subsection{Economic Factors}

Most households had very low economic status. $60 \%$ experienced some degree of food insecurity. [28] showed $69.2 \%$ of food insecurity among households. This study concluded that households that were food insecure had very low socio- economic status and caregivers having low level of education [28]. This study also submitted to monotonous diets which aggravated deficiencies in micronutrients. Other researches showed that caregivers could not feed their children protein sources such as meat, eggs or beans due to lack of money [28]. [20] stated that poverty increases levels of allocation of resources even food which to a greater extent affects the nutritional status of the entire household which also determines nutritional status of the child [1]. According to [24] children from insecure households are less likely to recover. [29] argued that, in most disadvantaged and undernourished communities, the only high quality food in the diet of the child is breast milk. Thus the nutritional status of the child is compromised due to lack of sufficient complementary or supplementary foods so as to meet the increasing demands of nutrients as there is increase in the child's development. Household income has effect on the household's nutritional status and thus is of paramount importance. It has been noted that access to economic resources is controlled by men such that the health of the child and mother depends greatly on the male figure who is more dominant [30]. This is in line with [25], who stated that sex of household head is designed to potray legal and societal advantages. It has been argued that improving household food security is necessary but not sufficient to improve nutritional status of children [28]. [25], agrees that nutritional status of a household member is directly affected by the household's food security.

Children who do not skip RUTF supply are 4 times more likely to recover. We assumed that this is attributed to its medicinal properties. The child has greater chances of relapse due to skipping of supply and thereby affecting the rate at which the child recovers. In addition to this, the chances of child recovering not having difficulties to access health centre are to 2.25 times more as compared to those encountering difficulties. These difficulties were mainly due to economic constraints as they lived far from the health centres. It is recommended that health centres must be plenty and close to where people live.

\subsection{Caregiver Knowledge}

Child recovery with caregivers who have secondary level of education is 6 times more as compared to those with primary school level. These findings are consistent with those of [27], who concluded that mothers who are educated are better aware of the requirements that are nutritionally essential to the child and thus povide improved care. This study showed that most caregivers had primary level of education and a few having reached secondary level. In some study, $46 \%$ caregivers had primary level and only $2 \%$ having secondary level [26]. According to Schnepf [25], caregiver education potrays the intellectual environment in which children are growing. He further noted that the level of education shows the ability of the caregiver to make informed decisions concerning good care practices and acquisition of food. Accoring to [30], mothers can be acquainted with knowledge on proper child care practices but has very little importance if the other partner is not involved. 
Regression analysis that was carried out in Nigeria showed that child age, gender, calorie intake and education are determinants which affect the rate at which the child will recover [24]. [22] concur when they argue that education affects the caregiving practices as this determines the extent to which one can process information and being acquainted with skills as well as being able to maintain sanitation in the environment. [26] noted that educated women tend to be active participants in the working population such that there is diminished activity which leads to reduced breast feeding time. There is also insufficient, time for healthy and nutritious food preparation which affect the child's nutrition status which has impact on the recovery rate. Public services are to be made aware that the child's nutrition status is put at risk if breastfeeding mothers fail to get adequate time to feed their babies. [31], stated that the time spent in preparing food, breast feeding and accessing health care services are of paramount importance as they affect the child's nutritional status and recovery.

Our findings showed that most of the households had low economic status but [22] argue that urbanisation has a positive effect on the child's nutritional status as it is associated with better income and education, access to health care facilities as well as better information health wise as compared to rural areas. Futhermore, [25] argues that rural children appear to recover from malnutrition as compared to urban children who tend to maintain higher levels of malnutrition and suppports his idea suggesting that urban children have no improved nutritional status despite access to the health infrastructure as it is essentially curative and not preventitive. Some caregivers did not uderstand the child's condition, causes and its effects.

\subsection{Caring Practices}

Breast feeding children have $89 \%$ chances of recovery. Breast milk contains antibodies that are responsible for fighting infections since malnourished children are susceptible to infections thus the severity is therefore reduced In addition to this, results have shown that children weaned after reaching 24 months are 7 times more likely to recover. This is in line with Hellen Keller International (HKI) which states that it is essential to breast feed a child until he or she reaches 2 years as they are prone to risk of malnutrition. Recovery increases as antibodies present in breast milk resist infections and allow right amounts of nutrients to be absorbed by the body. [32] argued that prolonged breast feeding tend to be positively associated with anthropometry in the poor and the opposite is true for the group with the highest income. Breast fed children have an increased growth rate unlike those who have been weaned [32]. This is so because children breast fed for over 1 year are prone to receiving less nutrients than those weaned earlier. It has also been noted by [32], that milk volume in the second year of breast feeding is lower than in the first. [12] argues that healthy stature at the age of 2 best reflects educational and economic success which is achieved by proper nutrition and breast feeding for the first 2 years of life. [33], concluded that prolonged breast feeding causes anorexia as child is most likely to reduce intake of supplemental foods as appetite is satiated at the breast. [34], argued that breast fed children tend to be more malnourished than non-breast children. It was noted that risk of dying was 6 times higher in children not breast feeding. Since breast milk is both food and drink and since it is rich with antibodies, it is recommended that mothers should breast feed upto about 2 years. It is safe and healthy.

\subsection{Health Factors}

Children below 18 months of age have $57 \%$ more chances of recovering. It has been noted in other researches that malnutrition is more prevalent between 6-24 months after which it is difficult to correct. This means that the low percentage of recovery of children above 18 months is possibly attributed to that, among other factors which may affect recovery. This has been supported by findings summarised by [22], that those above 18 months of age have grown into positions that they can find means of getting something to consume, for example, eating at a friend's house while they play; when their household has little or no food. [25] argues that children above 18 months of age correspond to the weaning period when supplemental foods are initiated which are often of low nutrient value in which food preparation may occur in insanitary conditions.. For example, some of the care givers fed children with sadza and soup with no protein source.

Complementary feeding practices were less than optimal as there were insufficient Infant and Young Child Feeding (IYCF) practices. The same diet was offered to the child causing the child to deny food as it became monotonous. This is in agreement with [28] who showed that children who failed to recover were being fed with more of energy giving foods with no or little protein sources due to lack of knowledge and some due to economic constraints. Children were also offered meals only at times when the rest of the family would eat. In some cases, we found out that a child aged 11 months would consume 2 or 3 meals per day yet they have high nutrient needs due to their rapid growth rate. This further reduced the recovery rate of the children. Most of the caregivers in this study fed children at the minimum acceptable diet for age and also fed at appropriate frequency thereby attributing to recovery. Stunted children have $89 \%$ less chances of recovering as compared to those not stunted. Research stated that by the time stunted children are clinically identified, permanent growth retardation is likely to have occurred [12].

(Seventy-five) $75 \%$ of children failed to recover when ill mother did not receive medication and $66.7 \%$ recovered when ill mother received medication. It is biologically plausible that when the caregiver is ill, the health of the child is likely to be compromised. Breast feeding and food preparations are affected to a greater extent and the nutritional status is therefore affected. This is in line with [25]'s findings that an individual health outcome affects nutritional status directly as illness reduces appetite, causes 
infections and absorption of nutrients is impaired.

\subsection{Household Food Sharing Practices}

RUTF was shared among the household members especially amongst the children as a coping strategy as they encountered challenges in accessing food to eat due to economic crisis. This to a greater extent compromised the child's health and consequently the recovery rate as the child would not consume the recommended daily ration. From the nutritional education that they are given on admission into the therapeutic feeding program, the caregivers are advised to feed plumpy nut directly from the packet, but $35 \%$ of them mixed plumpy nut with other foods and liquids so that it is ingested easily. We assumed that the medicinal properties of RUTF were thus distorted. The child should consume other foods in addition to RUTF so as to boost the child's nutritional status. This was also affected by the care giver's level of education.

\subsection{Cultural and Religious Factors}

Due to cultural practices, some foods such as beans and legumes were consumed sparingly by infants despite being very good sources of proteins. Some of the households indicated that they afforded such seeds and legumes but rather sold them as a source of income. This showed how deep rooted they are with their culture. It has been noted that the foods were not consumed due to poverty but due to traditional and cultural food practices. [35] also stated that gestation and lactation period also causes deprivation of nutrients which can also affect the nutritional outcome in the new born child. Findings also indicated that many of the care givers performed the traditional way of cooking porridge whereby mealie meal is sieved. This causes a great deal of nutrient loss [35]. Some care givers stated that they discard cooking water from cereals, reducing the nutritive value, unkowingly. It was also found that some caregivers (15\%) endulged in practices of abrupt weaning and short-term breastfeeding due to early pregnancy which contributes to poor infant growth. The specific food beliefs and practices which deprive caregivers and children of the nutritional benefits from certain foods cause their health to be compromised and thus affected recovery rate. [35] noted that some caregivers assume that fat babies are healthy especially when the stomach protrudes which is not the case. Instead the child is given more of energy-giving foods than fruits and vegetables as well as legumes. Grandmothers are known to have quality health practices in many cultures such that the child suffers materal deprivation and consequently have impact on health. In addition to this, misconceptions which state that "children are gifts from God" such that they tend to be polygamous having a great impact on the economic status due to increase in the family size. There are material and child health customs which cause people not to consume certain foods even though they are available in their community and affordable. This causes children fail to recover when malnutrition sets in due to religious practices.
Caregivers stated that they undergo excessive fasting for all household members including young children such that the child's nutritional status is compromised and affects recovery rate. [35] highlighted that the cultural practices of vegetarians cause them to be susceptible to Vitamin B12 deficiency. They further stated that deprivation of beef or pork due to religious practices will not affect the nutritional outcome as long as they have alternatives to that. Practices that men eat first and women last contribute to high infant and mortality rates.

\section{Conclusion}

The majority of the findings indicated that socio-economic factors, level of education and caring practices of the caregiver and the cultural practices to a larger extent contributed to the lower than expected recovery rates of HIV negative children on the therapeutic feeding program. Caregivers' level of education has great impact on the recovery rate of the child as it is related to the care-giving practices which determine the extent, to which one can process information, acquires skills and ensures sanitation of the environment. Furthermore, the evidence gathered strongly points to the conclusion that the therapeutic program is useful however; there is need for its consistent supply to avoid relapse and greater number of defaulters. The family size also affects the household's economic status. It was also concluded that care givers of the children are mostly their biological mothers who have diminished caring practices which affect the child's recovery rate. Cultural practices are to a lesser extent contributing to the lower recovery rates as compared to the socio-economic factors. It has been concluded that, there is less knowledge on the household food sharing practices and calls for improvements through health workers. We also call for the beneficiaries of the therapeutic program to get food rations from supplementary feeding programs to curb the food insecurity problem. The Zimbabwean government should spend more money on quality nutritional programs to improve state of malnutrition. We recommend that there is need for more nutrition campaign in an effort to promote health. The Ministry of Health and Child Welfare should ensure that RUTF stock rapture does not occur to avoid relapse so that beneficiaries will not default; thus consistent supply of RUTF is required. The pregnant and lactating mothers should be taught to make use of the readily available foods which are cheaper and nutritious. Non-governmental organisations such as CARE International should increase the projects of home gardens to increase food diversification.

The study was limited to an urbanised sample. A wider range including the rural participants is recommended for future studies for external validation.

\section{Acknowledgements}

We acknowledge and want to thank all the participants who took part in the study including the staff at GHDHO who assisted hither and thither. 


\section{References}

[1] Smith, L.C. \& Haddad, L. (2000). Explaining child malnutrition in Developing countries. A cross- country analysis. Washington D.C. International Food Policy Research Institute.

[2] Ramalingaswami, V, Johnson, U \& Rhohde, J. (1996). The progress of Nations, Unicef, 10- 21.

[3] Ministry of Health and Child Welfare, (2011). Prevention of Mother to Child Transmission of HIV. Annual Report. Zimbabwe Government.Harare, Govt. Printers.

[4] Fondo, J. K. (2013). Clinical outcomes of children aged 6-59 months with severe acute malnutrition admitted to Mbagatti district hospital. University of Nairobi.

[5] Kent, G. (2001). Freedom from want:human right to adequate food. Washington D,C: Georgetown University Press.

[6] Galiann, S. (2005). Water for life : The impact of the privatization of water services on child mortality. Political Economy, 113(1) no pages.

[7] Schroeder, D.G. and Brown, K.H. (1994). Nutritional status as a predictor of child survival: summarising the association and quantifying its global impact. The Bulletin World Health Organisation. 72(4), 569-579.

[8] Gailot, P. V., Cui, W., Fisk, N. M., \& Polak, D. J. (2007). Stem cell differentiation and expansion for clinical applicatios of tissue engineering. Cellular and Molecular Medicie, 11(5), 935-944.

[9] de Onis, M., Monteiro, C., Akre, J., \& Clugston, G. (1993). The worldwide magnitude of protein- energy malnutrition:an overview from the WHO global database on child growth. Bulletin of the world health organistaion, 71(6), 703-712.

[10] Muller, O., \& Krawinkel, M. (2005). Malnutrition and health in developing countries. Nutrition, 173(2), 279-286.

[11] Black, R. E., Allen, L. H., Butta, Z. A., Caulifield, L. E., de Onis, M., Ezzati, M. (2008, January 17). Maternal and child under nutrition: global and regional exposures and health consequences. Glasgow, U.K.

[12] Bertini, C. (2003). Meeting the challenge to improve complementary feeding. UK: Lavenham Press.

[13] Murray, S. (2006). Poverty and health. Public heath nutrition, 174(7), 923-925.

[14] Frankenberger, T. (1996). Measuring household livelihood security: an approach for reducing absolute poverty. Food forum, 34, 1-5.

[15] Engle, P., Menon, P., \& Haddad, L. (1999). Care and nutrition concepts and measurement. World Development, 27(8), 13091337.

[16] Martorell, R., Ramakrishnan, D., Schroeder, G., Melgar, P., \& Neufeld, L. (1998). Intrauterine growth retardation, body size, body composition and physical performance in adolescence. Clinical nutrition, 51 (543-553).

[17] Kapil, U. (2009). Ready to use therapeutic food (RUTF) in the management of severe acute malnutrition in India. Therapeutic Nutrition, 46(4), 338-406.
[18] Patel, M., Sandige, H., Ndekha, M., Briend, A., Ashorn, P., \& Manay, M. (2005). Supplemental feeding with ready to use therapeutic food in Malawian children at risk of malnutrition. Health Population Nutrition, 23(3), 351-357.

[19] Komrska, J. (2000). Increasing access to Ready-to-Use Therapeutic Foods. UNICEF

[20] Bomela, N. (2002). Child nutritional status and household patterns in S.A. Food, Agriculture, Nutrition and Development., 80-87.

[21] Choudhury, K. K., Haufi, M. A., Rasheed, J., \& Bhuiya, A. (2000). Gender inequality and severe malnutrition among children in a remote rural area in bangledesh. Health Population Nutrition, 18(3), 123-130.

[22] Chirwa, E. W., \& Ngalawa, H. (2006). Determinants of child nutrition in Malawi. New York: Mc Graw Hill.

[23] Schiff, M., \& Valdes, A. (1990). Nutrition: alternative definitions and policy implications. Economic Development and Cultural Change, 38(2), 281-292.

[24] Babatunde, R. O., Olagunju, F. I., Fakayode, S. B., \& Ojofe, S (2011). Prevalence and determinants of malnutrition among under-5 children of family households in Kwara state Nigeria. Agricultural Science, 3(3), 227-244.

[25] Schnepf, R. D. (1992). Nutritional status of Rwanda households: survey evidence on the role of household consumption behaviour. Washington D,C: CFNPP publications.

[26] Glick, P., \& Sahn, D. E. (1998). Maternal labour supply and Child nutrition in West Africa. Bulletin of Economics and Statistics, 160(3), 325-355.

[27] Webb, P., \& Block, S. (2004). Nutritional Information and formal schooling to child nutrition. Economic Development and Cultural Change, 5(5), 801-820.

[28] Osei, A., Pooja, P., Sipiro, D., Neilson, J., Shrestha, R., Talukder, Z., et al. (2010). Household food insecurity and nutritional status of children aged 6-23 months in Kailai Districtof Nepal. Food and Nutrition, 31(4), 499-509.

[29] Rohde, J. E. (1988). Breast feeding beyond 12 months. UK: Oxford University Press.

[30] Mwangombe, M., Prentice, A., \& Nweneka, C. (2010). Determinants of appropriate child health and nutrition practices among women in rural Gambia. Health pollution nutrition, 28(2), 167-172.

[31] Huffman, S. (1997). Women activities and child Nutrition food policy:intergration supply, distribution and consumption. Baltimore: John Hopkins University Press.

[32] Cesar, G., Huttly, S. R., Fernando, C. B., Matrices, J. C., \& Vanghan, J. P. (1991). Prolonged breast feeding and Malnutrition: Confounding effect modification in a Brazilian cohort study. Epidermiology, 2(3), 175-181.

[33] Tangermann, R. H., Serdula, M. K., Colebunders, R., \& Handl, F. (1988). Breast feeding for a year. UK: Oxford University Press.

[34] Briend, A., \& Bari, A. (1989). Breast feeding improves survival but not nutritional status of 12-35 months old in rural Bangladesh. Clinical Nutrition, 43(9), 603-609. 
[35] Ogunjuyigbe, P. O., \& Ojofetimi, E. O. (2001). Culture and feeding practices: major underlying cause of childhood malnutrition in developing countries. Tropical Paediatrics, 16(2), 24-31. 